$$
\text { BNL-47965 }
$$

INFORMAL REPORT

\title{
Tests of Hercules/Ultramet CVD Coatings in Hot Hydrogen
}

Peter E. Vanier, Robert E. Barletta, John Svandrlik, and Jay Adams

\author{
Reactor Systems Division \\ Department of Nuclear Energy \\ Brookhaven National Laboratory \\ Upton, NY 11973
}

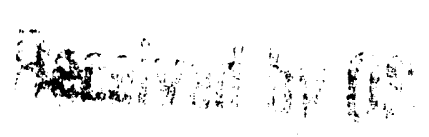


DISCLAIMER

This report was prepared as an account of work sponsored by an agency of the United States Government. Neither the United States Government nor any agency thereof, nor any of their employees, nor any of their contractors, subcontractors, or their employees, makes any warranty, express or implied, or assumes any legal liability or responsibility for the accuracy, completeness, or usefulness of an $\ddot{y}$ information, apparatus, product, or process disclosed, or represents that its use would not infringe privately owned rights. Reference herein to any specific commercial product, process, or service by trade name, trademark, manufacturer, or otherwise, does not necessarily constitute or imply its endorsement, recommendation, or favoring by the United States Government or any agency, contractor or subcontractor thereof. The vicws and opinions of authors expressed herein do not necessarily state or reflect those of the United States Government or any agency, contractor or subcontractor thereof. 
BNL- -47965

DE93 005533

\section{Table of Contents}

\section{Page No.}

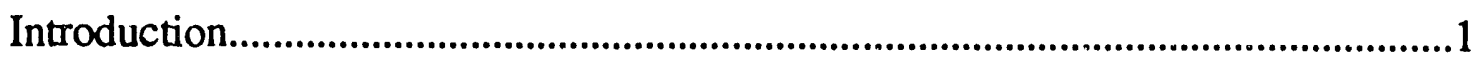

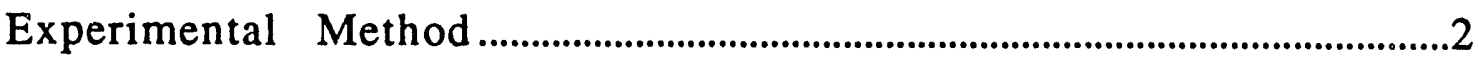

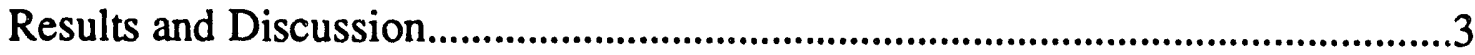

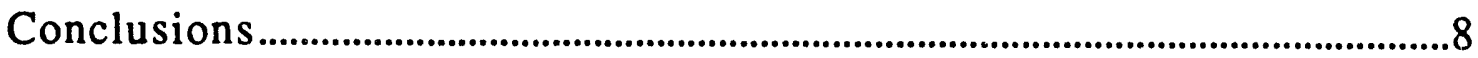




\section{List of Figures}

Page No.

Figure 1. Cumulative percentage of carbon weight loss for three samples of carbon-carbon coated with CVD NbC, heated in hydrogen to (A) $2500 \mathrm{~K}$, (B) $2800 \mathrm{~K}$, and (C) $3000 \mathrm{~K}$.

Figure 2. Multifaceted grains at surface of CVD NbC coating as received. Typical intergranular crack is seen running vertically.

Figure 3. Array of intergranular cracks in CVD NbC coating as received. The cracks appear to follow roughly the bundles of fibers in the 3-D weave.

Figure 4. Array of cracks in CVD NbC coating after heating at $3000 \mathrm{~K}$ for 42 minutes in He. Note spalled region.

Figure 5. Cross-section of CVD NbC coating as received. Note very fine grains at interface with carbon-carbon.

Figure 6. Cross-section of CVD NbC coating after 42 minutes anneal in $\mathrm{He}$ at $3000 \mathrm{~K}$. The grains are now coarse, and extend all the way through the coating. 


\title{
Tests of Hercules/Ultramet CVD Coatings in Hot Hydrogen
}

\author{
P.E. Vanier, R.E. Barletta, J. Svandrlik, J. Adams
}

Reactor Systems Division

Department of Nuclear Energy

Brookhaven National Laboratory

Introduction

A systematic effort to produce niobium carbide coatings for the protection of carbon-carbon components from erosion by hot hydrogen has recently been undertaken by Hercules in collaboration with Ultramet. The method used was chemical vapor deposition (CVD) in which the niobium is supplied in the form of a volatile chloride and the carbon is supplied by a gaseous hydrocarbon. The carbon substrate is held at some temperature where these gases react with each other at the surface and form the coating. This process is to be contrasted with the chemical vapor reaction (CVR) method, where no gaseous hydrocarbon is supplied, and the carbide is formed by reaction with the substrate at considerably higher temperatures than those used in the CVD process.

The intention was to adjust the process parameters so as to produce coatings which were adherent and impermeable to hydrogen. The reasons given for pursuing this approach were as follows. Firstly, since the CVD process occurs at moderate temperatures $(1300-1500 \mathrm{~K})$ scale-up of a CVD process to coat large objects was assumed to be simpler than for a CVR process. Secondly, since the film morphology is affected by the process conditions, it might be possible to prepare a favorable morphology for a particular application by finding the optimum conditions empirically. Thirdly, the cracks which develop in the coating after cooling from the deposition temperature (due to a mismatch in thermal expansion) should be less important than in coatings deposited at higher temperatures. Such cracks were blamed for the so-called "mid-band corrosion" problem in the NERVA project, where the most rapid erosion in hydrogen was observed in locations where the temperature was around $1400 \mathrm{~K}$. This supposition has recently been questioned in reports on isothermal testing of coated carbon-carbon specimens. ${ }^{1}$

\footnotetext{
${ }^{1} R$. Barletta, et al., "Carbon erosion in hydrogen - the midband problem revisited", Tenth Symposium on Space Nuclear Power Systems, Albuquerque, NM January, 1993, to be published.
} 
This report describes the results of testing of a series of specimens of Hercules carbon-carbon coated with $\mathrm{NbC}$ at Ultramet by the CVD process. The tests consisted of heating in $\mathrm{He}$ or $\mathrm{H}_{2}$ at a high rate, holding at a constant temperature for specified durations, and cooling rapidly. Some samples were heated repeatedly, while others were tested only once. Weight losses in the specimens provided a quantitative measure of the degree of protection to the substrate provided by the coating. Microscopic examination, including SEM images of the cross-section of the coatings, was used to elucidate the processes occurring during the tests.

\section{Experimental Method}

The specimens were cylindrical pieces of 3-D carbon-carbon with a diameter of about $6.3 \mathrm{~mm}$ and a length of $6.3 \mathrm{~mm}$, having an external (geometrical) surface area of $1.9 \mathrm{~cm}^{2}$. Each piece was weighed before being placed in a graphite crucible coated with $\mathrm{NbC}$. As described in previous reports, the crucible was placed in a graphite susceptor sitting on a pedestal tube through which the test gas (hydrogen or helium) flowed. A hole in the lid of the susceptor allowed the surface of the specimen to be viewed by a two color pyrometer. The pedestal and susceptor assembly were enclosed in a quartz tube filled with flowing $\mathrm{He}$ which mixed with the test gas emerging from the crucible, before being released to the ductwork of the surrounding hood.

The susceptor, crucible and specimen were heated within 30 seconds to the test temperature using a $10 \mathrm{~kW}$. Lepel inductively coupled rf power supply. Under the control of a Macintosh computer running LabView software, the gas flowing through the crucible was switched from $\mathrm{He}$ to $\mathrm{H}_{2}$ after the temperature had settled. A slight adjustment was made in the rf power to compensate for the difference in conductivity of the two gases. After a preset exposure time had expired, the hydrogen was switched back to helium, and the rf power was shut off under computer control. The specimen was weighed at room temperature and examined under the optical microscope. Testing was repeated several times until obvious holes had appeared in the coating, exposing the carbon to rapid attack by the hydrogen.

At various stages in the test, some specimens were also. examined under the scanning electron microscope, to look for changes in grain size, crack widths, and coating integrity. Cross-sectional images of the coatings were obtained by cutting some specimens in half with a diamond wheel and polishing the cut surfaces. The grain boundaries were revealed by etching for 30 seconds in a 1:1:1 mixture by volume of $\mathrm{HF}, \mathrm{HNO}_{3}$ and $\mathrm{H}_{2} \mathrm{SO}_{4}$. 


\section{$\underline{\text { Results and Discussion }}$}

Of the seven specimens from the same CVD run that were received, five were tested in hydrogen, one was tested in helium, and one was sectioned and examined in the SEM without any heat treatment. The cumulative weight losses measured during multiple heating cycles at three different temperatures are plotted in Figure 1. In each case, a smooth curve has been drawn through the data points as an aid to the eye, but no model is assumed for the shape of the curve. These results differ from earlier tests of $\mathrm{NbC}$ coatings on graphite, in which the weight loss was linear with time, and could be represented by a unique rate (i.e., slope) at each temperature. In this case, the weight loss is non-linear in time, and clearly accelerates as the sequence of tests proceeds.

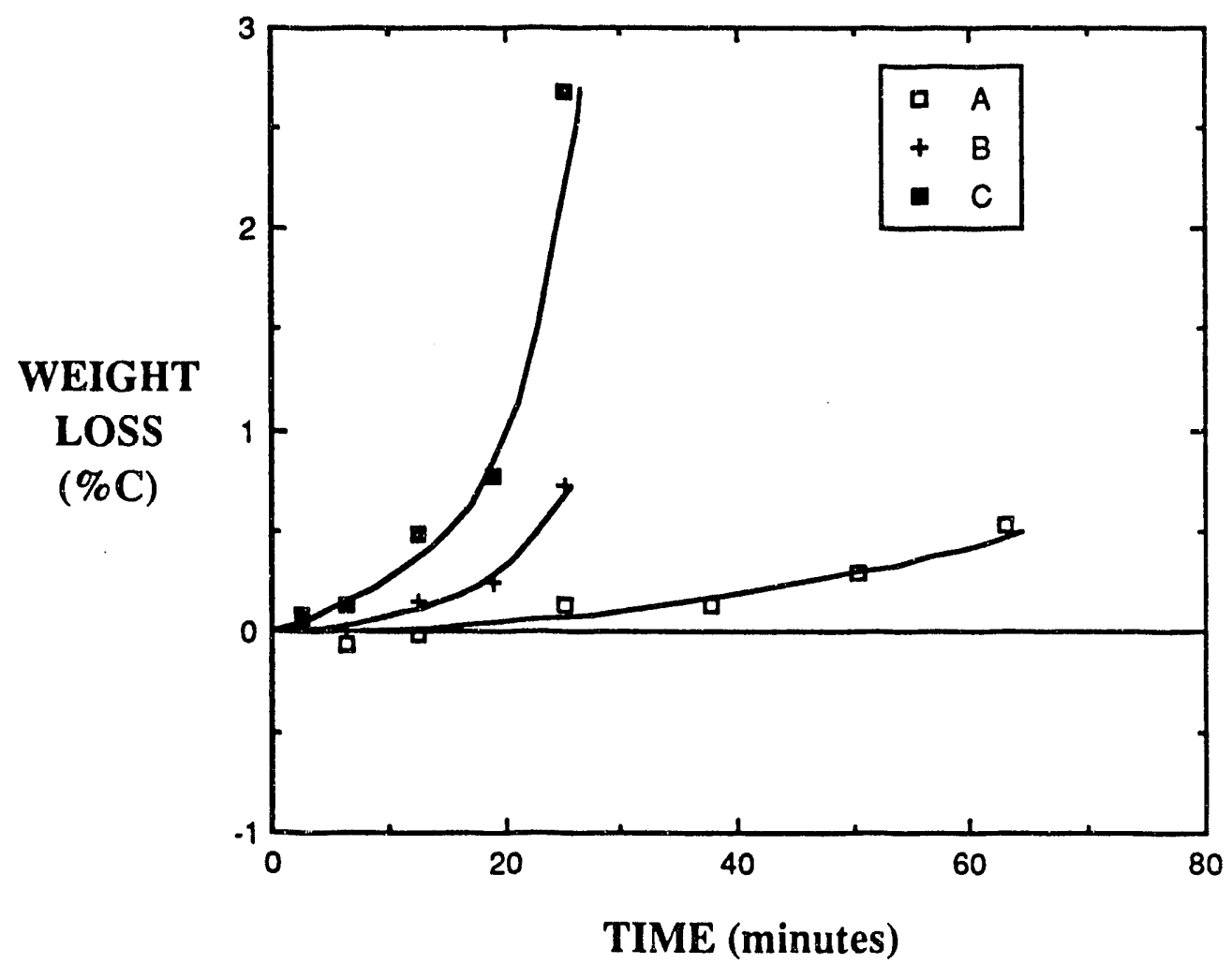

Figure 1. Cumulative percentage of carbon weight loss for three samples of carboncarbon coated with CVD NbC, heated in hydrogen to (A) $2500 \mathrm{~K}$, (B) $2800 \mathrm{~K}$, and (C) $3000 \mathrm{~K}$.

As one might expect, the removal of carbon occurs more rapidly at higher temperatures than at lower temperatures, in agreement with the previous data which showed that the process was thermally activated.1 In this case, however, it is difficult to determine either absolute rates or an activation energy. Nevertheless, one can state that $99 \%$ of the carbon remained intact after heating for about 20 minutes in hydrogen at the highest temperature. By 
comparison, an uncoated specimen of graphite loses $3.7 \%$ of its weight in 2 minutes of exposure to hydrogen at the same temperature. Using a linear interpolation for the uncoated graphite, this corresponds to a time of about 30 seconds to reduce the weight to $99 \%$. This result shows that the coatings do afford a certain amount of protection to the carbon-carbon substrate, but that this protection is limited in duration to about 10-20 minutes.

Scanning electron microscopy was used to investigate the nature of the degradation and failure of the coatings. The microstructure of the $\mathrm{NbC}$ as received showed equiaxial grains which were multi-faceted at the external surface of the coating, giving a rough appearance as in Figure 2. An array of fine intergranular cracks, probably formed on cooling from the deposition temperature, was also visible (Figure 2 and Figure 3 ). The coatings are in tension because the carbon-carbon has a coefficient of thermal expansion close to zero. These cracks tended to follow the underlying weave of the carboncarbon. After heating in helium or in hydrogen to test temperatures, the crack pattern became more evident as in Figure 4. This change probably results from putting the coating in compression at the high temperatures, where the NbC can relieve its strain by plastic deformation or creep. The rapid cooling would then cause larger cracks to develop as the coating contracted.

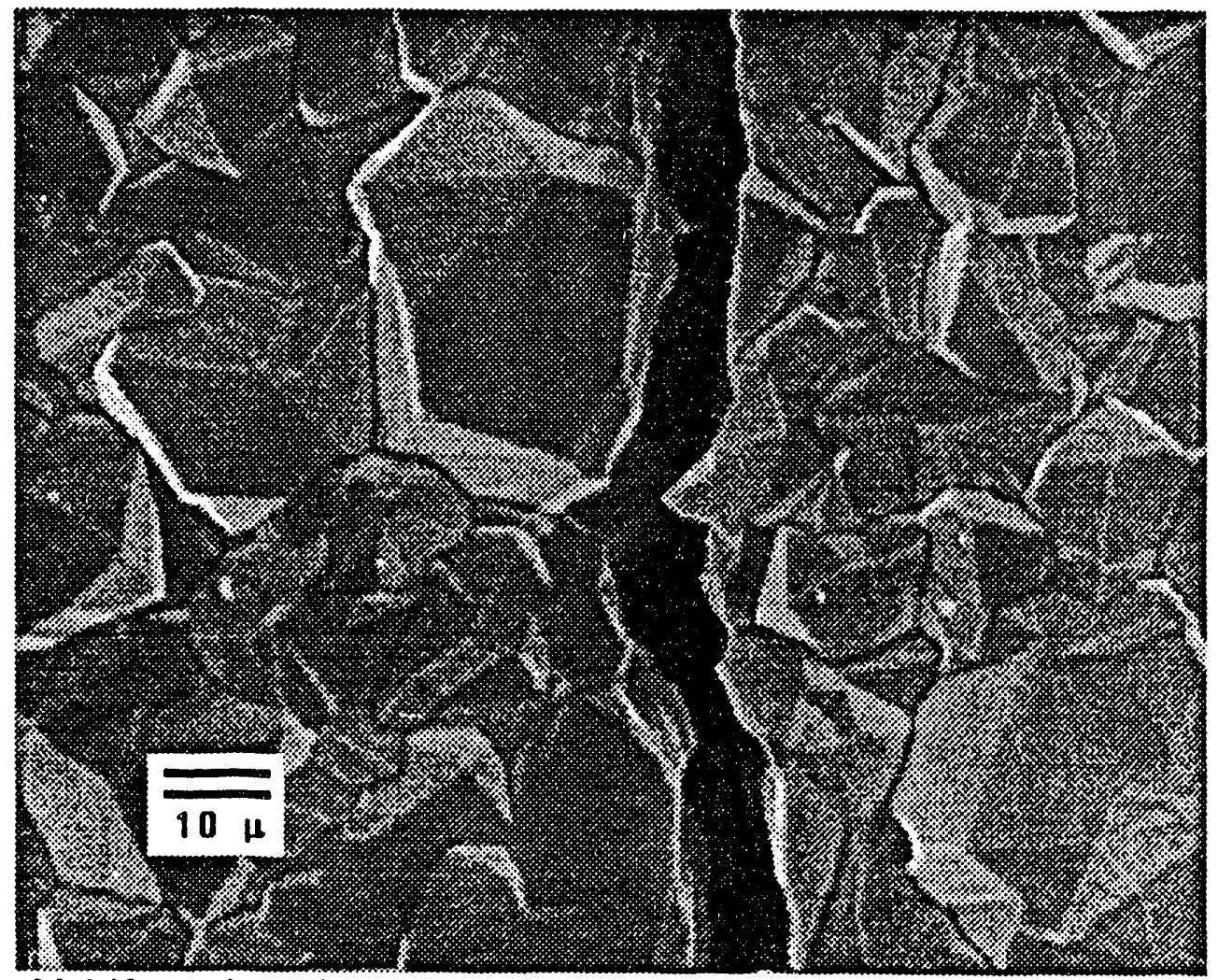

Figure 2. Multifaceted grains at surface of $\mathrm{CVD} \mathrm{NbC}$ coating as received. Typical intergranular crack is seen running vertically. 


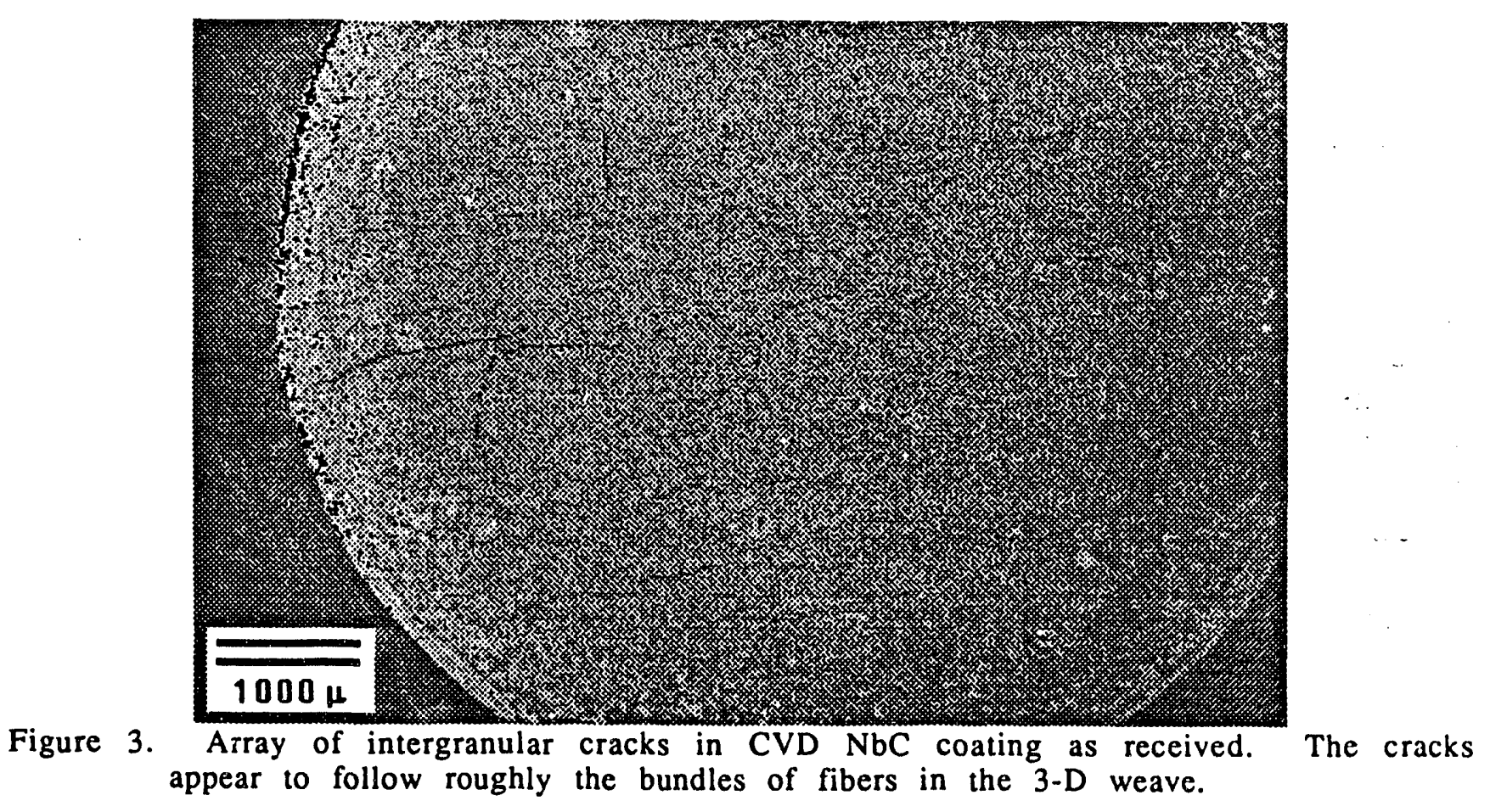

Figure 4 also shows an example of spalling of the coating during or after heating, in which the substrate is left exposed in a visible area. Each series of tests was terminated when the coating showed such visible signs of spalling. At that point, it was useless to continue, because although the carbon weight losses were negligible in $\mathrm{He}$, the loss of pieces of carbide coating would reduce the weight. Also, if the atmosphere were $\mathrm{H}_{2}$, the rate of reaction would be expected to rise sharply because of the increased area exposed. 


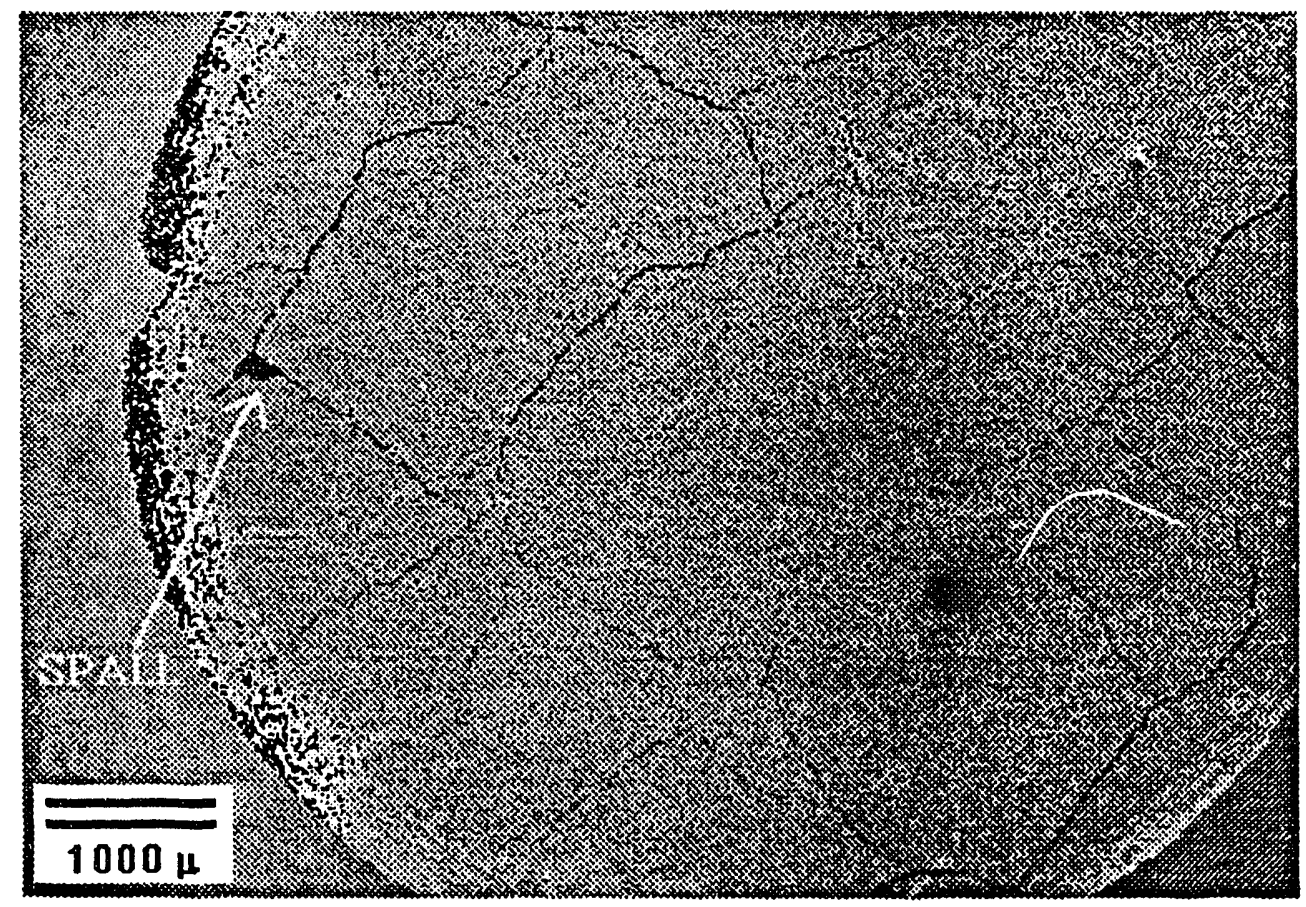

Figure 4. Array of cracks in CVD NbC coating after heating at $3000 \mathrm{~K}$ for 42 minutes in He. Note spalled region.

Figure 5 shows the section through a CVD coating as received. The larger grains at the outer surface of the coating rest on several layers of very much smaller grains at the carbon/ $\mathrm{NbC}$ interface. These small grains indicate that during the deposition process nucleation was rapid, but growth was slow for most of the nuclei. Some grains with preferred orientation grew more rapidly to form the outwardly visible coating. After heating in either $\mathrm{H}_{2}$ or $\mathrm{He}$, the small grains disappear, as shown in Figure 6. This process of recrystallization is driven by the reduction in free energy associated with grain boundaries. When the larger, more stable grains grow at the expense of the small grains, there is no reason for the new structure to adhere strongly to the substrate, even if the original small grains were strongly bonded. Therefore, the coating becomes fragile and easily spalled. This process makes the low temperature CVD coatings inherently unstable at high operating temperatures, regardless of the atmosphere. 




Figure 5. Cross-section of CVD NbC coating as received. Note very fine grains at interface with carbon-carbon.

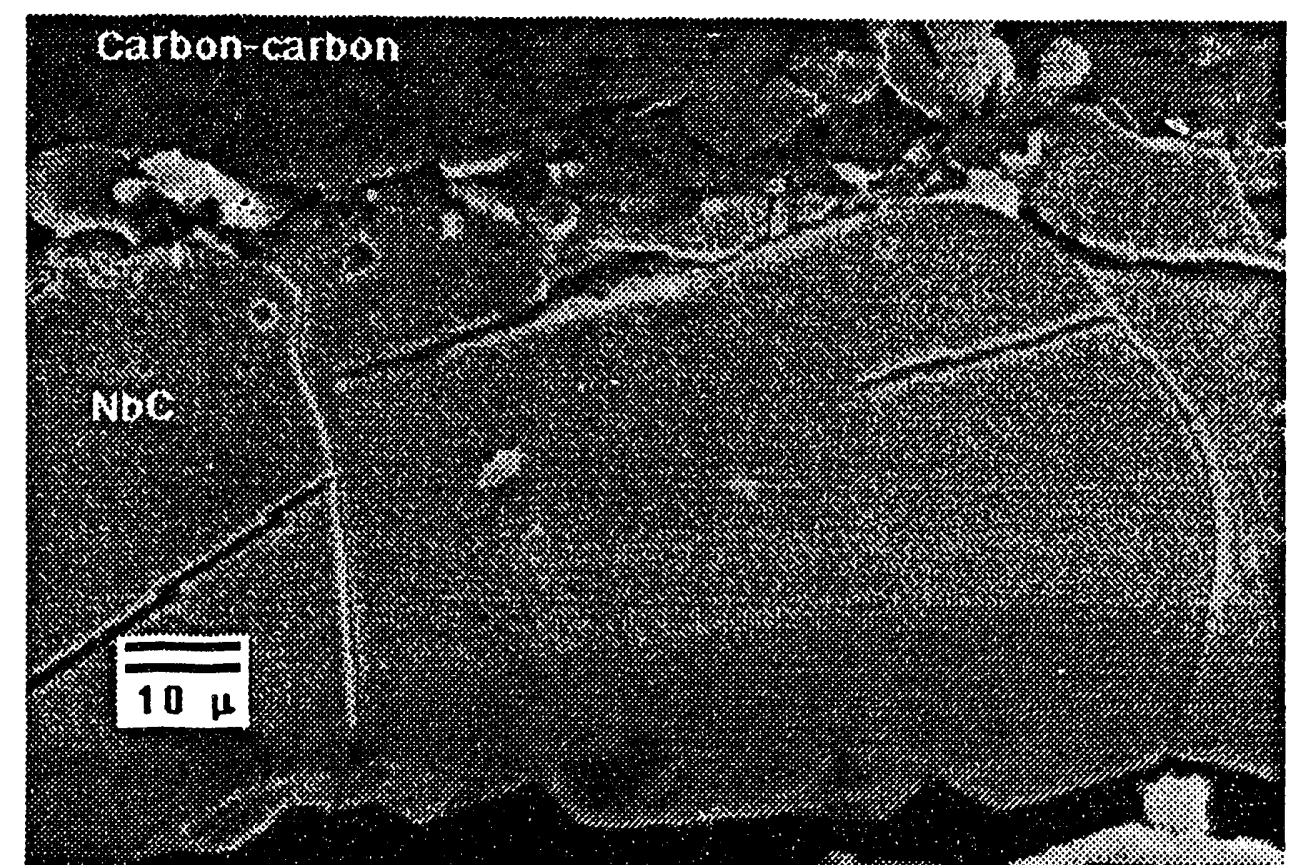

Figure 6. Cross-section of CVD NbC coating after 42 minutes anneal in He at $3000 \mathrm{~K}$. The grains are now coarse and extend all the way through the coating. 


\section{Conclusions}

The effort by Hercules and Ultramet to produce CVD NbC coatings, which protect carbon-carbon substrates from hot hydrogen, has had some success but with some limitations. The coatings increase the survival time at atmospheric pressure and low flow rate of hydrogen by about a factor of 40 over uncoated graphite at $3000 \mathrm{~K}$. However, the grain structure is not stable at these temperatures, and after about 10-20 minutes, the coating is subject to rapid degradation by spalling in visible chunks. Further experiments would have to be perfo:med to determine the effects of higher pressures and flow rates, for it is not clear how these factors would affect the survival time, considering that one of the main failure mechanisms is independent of the atmosphere. 

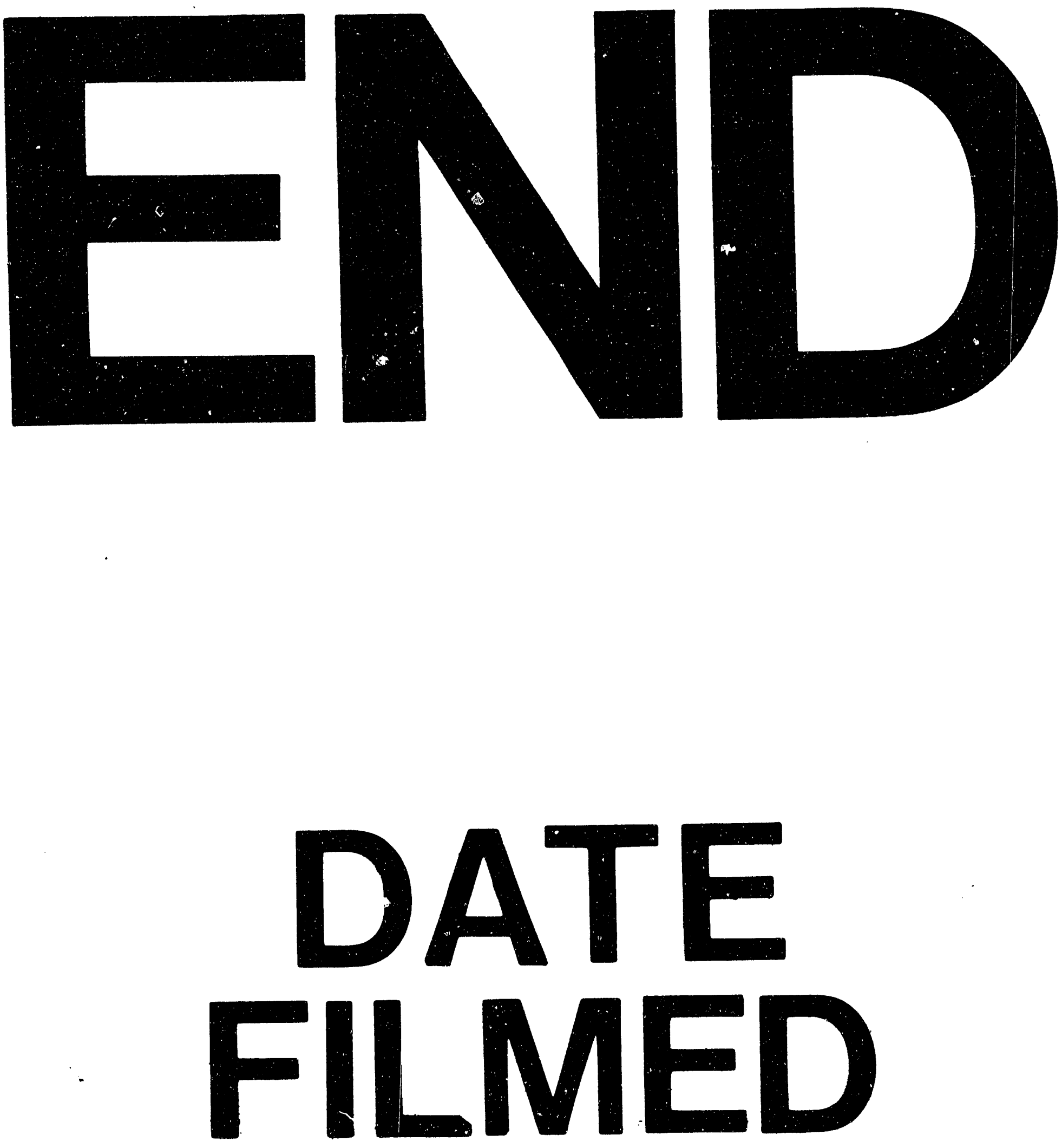

I

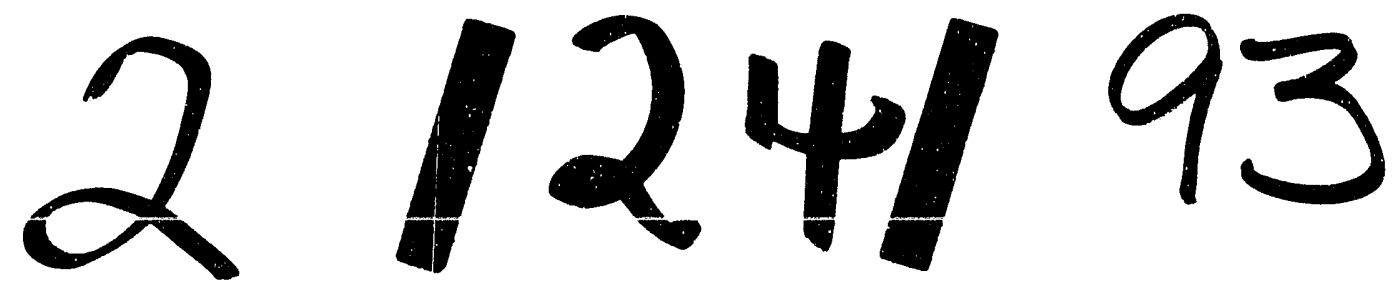


